Bề dày của các thành tim thai ở nhóm sản phụ có chỉ số kháng trở động mạch tử cung RI $>0,55$ lớn hơn một cách có ý nghĩa so với nhóm sản phụ có chỉ số $\mathrm{RI} \leq 0,55, \mathrm{p}<0,05$. Chỉ số VTI của tim thai nhi qua ĐMC, ĐMP ở nhóm sản phụ có chỉ số RI >0,55 cao hơn một cách có ý nghĩa với nhóm sản phụ có chỉ số $R I \leq 0,55$, $\mathrm{p}<0,001$.

Ớ các nghiên cứu về Doppler động mạch tử cung và tìm mối tương quan giữa RI với tình trạng bệnh lý TSG, đa số tác giả tìm ra ngưỡng giá trị RI tiên lượng tình trạng nặng của bệnh là $0,58^{9}$. Kết quả nghiên cứu của chúng tồi cho thấy điểm cắt RI là 0,55 có giá trị trong đánh giá sự thay đổi hình thái và chức năng tim thai. Thăm dò Doppler ĐMTC không những có giá trị tiên lượng tình trang thai mà còn có giá trị chẩn đoán nguyên nhân thai CPTTTC là về phía người mẹ mà cụ thể hơn là do nguyên nhân tuần hoàn của người mẹ. Kết luận này cũng tương tự như của Sudha Prasad (2017).

\section{KẾT LUÂ̂N}

1. Nghiên cứu cho thây chỉ số khối cơ thế (BMI), mức huyết áp tâm thu, huyết áp tâm trương và LDL-cholesterol của mẹ là những chỉ số lâm sàng có ảnh hưởng đến chức năng của tim thai toàn bộ, biểu hiện bằng chỉ số Tei thất phải và Tei thất trái $(p<0,05)$.

2. Chỉ số RI của động mạch tử cung tương quan thuận vói kích thuóc và bề dày thành tim thai $(p<0.05)$.

Ngưỡng RI > 0,55 cho thây sự khác biệt có ý nghĩa thống kê khi so sánh chỉ số tim ngực, bề dày thành tim, VTI ĐMC, ĐMP của tim thai có mẹ TSG và tim thai có mẹ khỏe mạnh với $p<0,05$.

\section{LờI CẢM ƠN}

Chúng tôi xin bày tỏ lòng biết ơn tới Lãnh đạo Bệnh viện Bạch Mai, khoa Phụ Sản, Viện Tim mạch Việt Nam và các phòng, ban của Bệnh viện Bạch Mai đã tạo điều kiện thuận lợi để hoàn thành nghiên cứu.

\section{TÀI LIÊU THAM KHẢO}

1. Ngộ Văn Tài. Một số yễu tố tiên lượng trong nhiểm độc thai nghén, Luận án tiến sỹ $Y$ học, Trường Đaai hoc Y Hà Nối. Published online 2001.

2. Ngô Văn Tài. Tiền sản giật và sản giật. In: Tiền Sản Giật và Sản Giật. 1st ed. Nhà xuất bản Y học; 2006:7-51.

3. Sibai B.M Ramadan K. "Pre-Eclamsia and Eclamsia", Sciarra.Obstet Gyneco, Vol .2, No.7, Pp.1-14.; 1995.

4. Comas M, Crispi F. Assessment of Fetal Cardiac Function Using Tissue Doppler Techniques. FDT. 2012;32(1-2):30-38. doi:10.1159/000335028

5. Dương Thị Bế. Nghiên cứu sự tác động của một số các yếu tố cận lâm sàng và lầm sàng trong nhiễm độc thai nghén taii Bệnh viên Phụ sản Trung ương trong 2 năm 2003-2004, luận văn tốt nghiệp bác sỹ chuyên khoa cấp II, Trường đại học Y Hả Nội.

6. Phạm Thị Mai Anh. Nghiên cứu thông số Doppler động mạch tử cung ở thai phụ tiền sản giật. Published online 2009.

7. Ayman Fouad Ahmed Sabry, Kumar S. Assessment of fetal cardiac function with maternal hypertension: Fetal echocardiography study. J Clin Exp Cardiolog. 2016;07(12). doi:10.4172/21559880.C1.063

8. Balli S, Kibar AE, Ece I, Oflaz MB, Yilmaz 0 . Assessment of fetal cardiac function in mild preeclampsia. Pediatr Cardiol. 2017;34(7):16741679. doi:10.1007/s00246-013-0702-8

9. Risk factors and clinical manifestations of pre-eclampsia - Ødegård - 2000 - BJOG: An International Journal of Obstetrics \&amp; Gynaecology - Wiley Online Library. Accessed November7, 2020. https:// obgyn.onlinelibrary. wiley. com/ doi/full/10.1111/j.1471-0528. 2000. tb11657.x

\title{
MộT SỐ YẾU TỐ LIÊN QUAN ĐẾN THỜI GIAN CỬA - KIM Ở BÊNH NHÂN ĐộT QUỴ NHỒI MÁU NÃO CẤP ĐƯợC ĐIỀU TRI TIÊU HUYỂT KHỐI
}

\section{TÓM TẮT}

\footnotetext{
${ }^{1}$ Trường Đại học Y Hà Nội,

2Bệnh viện Đại học Y Hà Nội,

${ }^{3}$ Bênh viên Bach Mai

Chiu trách nhiệm chính: Hoàng Bùi Hải

Email: hoangbuihai@hmu.edu.vn

Ngày nhận bài: 15.10 .2020

Ngày phản biên khoa họ: 20.11.2020

Ngày duyệt bài: 3.12.2020
}

\section{Đặng Trung Anh ${ }^{1}$, Hoàng Bùi Hải ${ }^{1,2}$, Mai Duy Tôn ${ }^{3}$}

Nghiên cứu nhằm mô tả một số yếu tố liên quan đến thời gian cửa - kim (DTNं), là thời gian từ khi bệnh nhân nhập viện đến khi bệnh nhân được dùng thuốc tiêu huyết khối ở các bệnh nhân đột quy nhồi máu não cấp. Đây là phương pháp hồi cứu mô tả tại bệnh viện Đại học Y Hà Nội và Bạch Mai trên 124 bệnh nhân đã được chẩn đoán nhồi máu não cấp và được điều trị tiêu huyết khối. Kết quả cho thây có phim chụp so não trước khi đến viên, liên hê trước với bệnh viện, vào viện trong giờ hành chính và thời gian nhập viện - thăm khám (DTE) ngắn là các yếu tố độc lập liên quan đến thời gian cửa - kim < 60 phút. Từ 
các kết quả này có thể giúp cải thiện quy trình và làm giảm được thời gian cửa - kim, từ đó nâng cao chất lượng điều trị bệnh nhân đột quy nhồi máu não cấp.

Tư khóa: Thời gian cửa - kim, đột quy nhồi máu não, nhồi máu não cấp, tiêu huyết khổi.

\section{SUMMARY \\ FACTORS ASSOCIATED WITH DOOR-TO- NEEDLE TIME IN PATIENTS WITH ACUTE ISCHEMIC STROKE TREATED BY INTRAVENOUS FIBRINOLYTIC}

The study aimed to describe factors associated with door-to-needle time (cưa - kim), the time from arrival to intravenous thrombolytic administration in patients with acute ischemic stroke. This was retrospective observational study at Hanoi Medical University and Bach Mai Hospitals on 124 patients who were diagnosed as acute ischemic stroke and treated with thrombolysis. The results showed that prehospital contact, admission during office hours and the length of door-to-examination (DTE) time were independent factors related to cứa - kim time less than 60 minutes. From these results, it was possible to improve the process and reduce the cưa - kim time, thereby improving the quality of treatment in patients with acute ischemic stroke.

Key words: door-to-needle, acute ischemic stroke, ischemic stroke, intravenous thrombolysis.

\section{I. ĐĂT VẤN ĐỀ}

Đột quy não là nguyên nhân chính gây tử vong hàng thứ 5 tại Mỹ, ${ }^{1}$ và là nguyên nhân gây tử vong hàng thứ 2 trên toàn thế giới. ${ }^{2}$ Tại Việt Nam, tî lệ bệnh nhân bị đột quy não mỗi năm vào khoảng $90 / 100.000$ dân. ${ }^{3}$ Chẩn đoán và điều trị đột quy. càng sớm thì tiên lượng của bệnh nhân càng tốt, đặc biệt là đối với các bệnh nhân đột quy nhồi máu não. Thuốc tiêu huyết khối đã được chứng minh cải thiện tỉ lệ sống và giảm nguy cơ tàn phế cho bênh nhân đột quy nhồi máu não. ${ }^{4}$ Tuy nhiên tỷ lệ bệnh nhân được điều trị bằng tiêu huyết khối vẩn còn chưa cao, vì cửa sổ điều trị bằng thuốc tiêu huyết khối cho nhóm bênh nhân đột quy nhồi máu não là rất hẹp ( $\leq$ 4,5 giờ), ${ }^{5}$ nên việc rút ngắn thời gian từ khi xuất hiện triệu chứng đến lúc được tiêu huyết khối có ý nghĩa lớn giúp cải thiên tiên lượng.

Tại Hà Nội, việc tiến hành điều trị tiêu huyết khối cho bênh nhân đến sớm còn chỉ định đã được thực hiện thường quy tại nhiều bệnh viện trung ướng và thành phố. Để nâng cao chất lượng điều trị đột quy nhồi máu não cấp, một trong các mục tiểu có thể thực hiện được là làm giảm thời gian cửa - kim, ${ }^{6}$ tức là thời gian từ khi bệnh nhân nhập viên vào cửa khoa cấp cứu đến khi được dùng thuốc tiêu huyết khối. Nghiên cứu đã cho thấy thời gian cửa - kim ngắn hơn có liên quan đến kết cục lâm sàng tốt hơn và tỉ lệ tử vong thấp hơn. ${ }^{7}$ Hướng dẫn năm 2018 của Hội Tim mạch/Hội Đột quy. Hoa kỳ về quản lý sớm bệnh nhân đột quy nhồi máu não cấp khuyến cáo mục tiêu cho thời gian cửa - kim là dưới 60 phút trên hơn $50 \%$ số bệnh nhân đột quy nhồi máu não được điều trị tiêu huyết khối. ${ }^{8}$ Đây cũng là điều kiện đầu tiên để đạt được chứng nhận Vàng cho đơn vị Đột quy của Hội Đột quy thế giới (WSO). Để đánh giá các yểu tổ rút ngắn cũng như kéo dài thời gian cửa - kim của các bệnh nhân đột quỵ nhồi máu não cấp, chúng tôi tiến hành nghiên cứu với muc tiêu: "Mô tả một số yếu tố liên quan đến thời gian cửa - kim ở bệnh nhân đột quy nhồi máu não cấp được tiêu huyêt khối".

\section{II. ĐỐI TƯỢNG VÀ PHƯƠNG PHÁP NGHIÊN CỨU}

1. Đối tượng nghiên cứu bao gồm bệnh án các bệnh nhân $\geq 18$ tuổi, đã được chẩn đoán là đột quy nhồi máu não và được điều trị bằng thuốc tiêu huyết khối đường tĩnh mạch. Tiêu chuẩn loại trừ bao gồm các bệnh nhân đột quy. trong viện, không xác định được thời điểm nhập viện, và các hồ sơ bệnh án không đủ thông tin.

2. Phương pháp nghiên cứu. Nghiên cứu hồi cứu mô tả, cõ mấu thuận tiện trong thời gian từ tháng 1/2019 - tháng 8/2020, tại Bệnh viện Đại học Y Hà Nội và Bệnh viện Bạch Mai. Các mẩu nghiên cứu được thu thập từ bệnh án lưu trữ và trên phần mềm quản lý bệnh viện (bệnh án điện tử). Thời điểm nhập viện được xác định là thời điểm bệnh án điện tử được thiết lập (ngày giờ vào viện trên bệnh án điện tử); thời điểm thăm khám, thời điểm tiêu sợi huyết và các thông tin khác được lấy từ bệnh án trong kho lưu trữ.

Thời gian cửa - kim (door-to-needle, DTN) được xác định là khoảng thời gian từ thời điểm nhập viện đến khi bệnh nhân được dùng thuốc tiêu huyết khối. Thời gian cửa - kim được xác định là kéo dài khi $\geq 60$ phút, dựa trên hướng dẫn của $A H A$ về điều trị sớm đột quy nhồi máu não cấp. ${ }^{8}$ Thời gian khởi phát - nhập viện (onset-to-door, OTD) là khoảng thời gian từ khi bệnh nhân xuất hiện triệu chứng đầu tiên đến thời điểm nhập viện. Thời gian nhập viện - thăm khám (door-to-exam, DTE) là khoảng thời gian từ thời điểm nhập viện đến thời điểm bệnh nhân được thăm khám. Thời gian khởi phát - điều trị (onset-to-treatment, OTT) là khoảng thời gian từ khi bệnh nhân xuất hiện triệu chứng đầu tiên đến khi bệnh nhân được điều trị tiêu huyết khối.

Các yếu tố trước viện được đánh giá bao gồm đến viện bằng xe cứu thương hay phương tiện khác, có liên hệ trước với bệnh viện hay không, 
thời điểm nhập viện trong hay ngoài giờ hành chính ( $8 \mathrm{~h}-17 \mathrm{~h}$ các ngày từ thứ 2 - thứ 6 , cộng thêm $8 \mathrm{~h}-12 \mathrm{~h}$ ngày thứ 7 nếu ở bệnh viện ĐHYHN) và thời gian khởi phát - nhập viện. Các yếu tố trong viện bao gồm mức độ nặng của đột quỵ. não cấp (thông qua điểm NIHSS) lúc nhập viện, thời gian nhập viện - thăm khám, kiểm soát huyết áp trước khi tiêu huyết khối và tiêu huyết khối tại phòng chụp phim. So sánh tỉ lệ số bệnh nhân có thời gian cửa - kim $<60$ phút và $\geq$ 60 phút ở các nhóm. Đưa vào mô hình hồi quy đơn biến và đa biến với các kết quả có số lượng bệnh nhân khác biêt có ý nghĩa thống kê.

3. Xử lý số liệu: Bằng phần mềm thống kê SPSS phiên bản 20 , dữ liệu được trình bày dưới dạng tần số và tỷ lệ \% với biến định tính; dạng trung bình \pm độ lệch chuẩn hoặc trung vị (tứ phân vị) đối với biến định lượng. So sánh sự khác biệt giữa các nhóm dùng thuật toán MannWhitney $U$ test hoặc $t$ test đối với các biến liên tục và $x 2$ test với các biến phân loại. Khác biệt có ý nghĩa thống kê khi giá trị kiểm định $p<0,05$.
Sử dụng hồi quy logistic đơn biến xác định các yễu tố liên quan đến thời gian cửa - kim < 60 phút hoặc $\geq 60$ phút, hồi quy logistic đa biến với các giá trị $p<0,2$ để xác định các yếu tố độc lập liên quan đến thời gian cửa - kim $<60$ phút hoăc $\geq 60$ phút.

4. Khía cạnh đạo đức nghiên cứu: Nghiên cứu quan sát, không làm thay đổi điều trị của bệnh nhân, thông tin của bệnh nhân được bí mật và kết quả nghiên cứu nhằm phục vụ nghiên cứu khoa học.

\section{KẾT QUẢ NGHIÊN CỨU}

Trong thời gian từ tháng $1 / 2019$ đến tháng 9/2020, nghiên cứu thu thập được 124 bệnh nhân có đủ tiêu chuẩn tham gia vào nghiên cứu, trong đó có 100 bệnh nhân tại bệnh viện Bạch Mai, 24 bệnh nhân tại bệnh viện Đại học Y Hà Nội. Các bệnh nhân được phân loại thành 2 nhóm theo thời gian cửa-kim: Dưới 60 phút (cửa - kim <60 phút) và trên hoặc bằng 60 phút (cửa - kim $\geq 60$ phút).

Bảng 1. Đặc điểm chung nhóm bệnh nhân nghiên cứu

\begin{tabular}{|c|c|c|c|c|}
\hline & $\begin{array}{c}\text { Chung } \\
(n=124)\end{array}$ & $\begin{array}{c}\text { cửa - kim }<60 \\
\text { phút } \\
(n=65)\end{array}$ & $\begin{array}{c}\text { cửa - kim } \geq 60 \\
\text { phút } \\
(n=59)\end{array}$ & P value \\
\hline Tuối $\left({ }^{\boldsymbol{x}} \pm \mathrm{SD}\right)$ & $66,23 \pm 13,51$ & $65,7 \pm 14,0$ & $66,8 \pm 13,0$ & 0,637 \\
\hline Nữ & $62(50 \%)$ & $29(44,6 \%)$ & $33(55,9 \%)$ & 0,208 \\
\hline \multicolumn{5}{|c|}{ Tiền sử bệnh tật } \\
\hline THA & $64(51,6 \%)$ & $35(53,8 \%)$ & $29(49,2 \%)$ & 0,601 \\
\hline ĐTÐ & $15(12,1 \%)$ & $5(7,7 \%)$ & $10(16,9 \%)$ & 0,114 \\
\hline RLLPM & $2(1,6 \%)$ & $2(3,1 \%)$ & $0(0,0 \%)$ & 0,174 \\
\hline Rung nhĩ & $7(5,6 \%)$ & $3(4,6 \%)$ & $4(6,8 \%)$ & 0,602 \\
\hline ĐQN cũ & $10(8,1 \%)$ & $7(10,8 \%)$ & $3(5,1 \%)$ & 0,246 \\
\hline \multicolumn{5}{|c|}{ Đặc điếm lâm sàng } \\
\hline Điếm NIHSS & $9(6-14)$ & $10(6-14)$ & $8(6-12)$ & 0,505 \\
\hline Huyết áp tâm thu & $\begin{array}{c}150(130- \\
170)\end{array}$ & $152(130-170)$ & $147(130-170)$ & 0,706 \\
\hline Huyết áp tâm trương & $80(78-90)$ & $80(80-97)$ & $80(70-90)$ & 0,693 \\
\hline ĐMMM & $7,3(6,1-8,9)$ & $7,3(6,2-9,1)$ & $7,3(6,0-8,4)$ & 0,986 \\
\hline INR & $\begin{array}{c}0,97 \\
(0,93-1,01)\end{array}$ & $\begin{array}{c}0,98 \\
(0,93-1,00)\end{array}$ & $\begin{array}{c}0,96 \\
(0,93-1,03)\end{array}$ & 0,776 \\
\hline
\end{tabular}

Khác biệt không có ý nghĩa thống kê về các đặc điếm chung giữa hai nhóm thời gian cửa - kim < 60 phút và cửa - kim $\geq 60$ phút.

Bảng 2. Các khoảng thời gian của bệnh nhân được tiêu huyết khối

\begin{tabular}{|c|c|c|c|c|}
\hline Thời gian & Tổng ( $n=124)$ & $\begin{array}{l}\text { cửa - kim < } 60 \\
\text { phút }(n=65)\end{array}$ & $\begin{array}{l}\text { cửa - kim } \geq 60 \\
\text { phút }(n=59)\end{array}$ & $\mathbf{p}$ \\
\hline Cửa-kim (cửa - kim) & $59(40-70,75)$ & $40(33-51)$ & $72(65-81)$ & \\
\hline $\begin{array}{c}\text { Khởi phát - Nhập viện } \\
\text { (OTD) }\end{array}$ & $103(72,25-161)$ & $101(79-161)$ & $111(60-150)$ & 1,0 \\
\hline $\begin{array}{c}\text { Khởi phát - điêu trị } \\
\text { (OTT) }\end{array}$ & $\begin{array}{c}160(125,75- \\
210)\end{array}$ & $142(120-205)$ & $185(145-225)$ & 0,02 \\
\hline $\begin{array}{c}\text { Nhập viện- Thăm } \\
\text { khám (DTE) }\end{array}$ & $9(0-15)$ & $5(0-10)$ & $13(5-20)$ & 0,002 \\
\hline
\end{tabular}


Giá trị trung vị của thời gian cửa - kim là 59 phút (tứ phân vị $40-70,75$ phút). Thời gian khởi phát - nhập viện là 103 phút, không có sự khác biệt có ý nghĩa giữa 2 nhóm có thời gian cửa kim $<60$ phút và $\geq 60$ phút (lần lượt là 101 phút và 111 phút). Thời gian khởi phát - điều trị là 160 phút, ở nhóm có thời gian cửa - kim $<60$ phút là 142 phút, ngắn hơn đáng kể so với nhóm có thời gian cửa - kim $\geq 60$ phút (185 phút). Thời gian nhập viện - thăm khám của nhóm bệnh nhân nghiên cứu là 9 phút (tứ phân vị 0 15 phút), ở nhóm có thời gian cửa - kim dưới 60 phút là 5 phút, ngắn hơn có ý nghĩa so với nhóm có thời gian cửa - kim $\geq 60$ phút (13 phút).

Nghiên cứu cho thây có $21 \%$ bệnh nhân đến viện bằng xe cứu thương; 12,9\% bệnh nhân được chụp phim sọ não (CT hoặc MRI) trước khi đến viện (tại bệnh viện tuyến trước); $11,3 \%$ bệnh nhân có liên hệ trước với bệnh viện; 44,4\% bệnh nhân nhập viện trong giờ hành chính, 19,4\% bệnh nhân có dùng thuốc hạ áp (nicardipin truyền tĩnh mạch) trước khi dùng thuốc tiêu huyết khối và 2,4\% bệnh nhân được dùng thuốc tiêu huyết khối tại phòng chụp phim.

\section{Bảng 3. Các yếu tố liên quan đến cửa - kim}

\begin{tabular}{|c|c|c|c|c|}
\hline Các biến & $\begin{array}{c}\text { Chung } \\
(n=124)\end{array}$ & $\begin{array}{l}\text { cửa - kim < } 60 \\
\text { phút }(n=65)\end{array}$ & $\begin{array}{c}\text { cửa - kim } \geq 60 \\
\text { phút }(n=59)\end{array}$ & $\mathbf{p}$ \\
\hline Đi xe cứu thương & $26(21 \%)$ & $16(24,6 \%)$ & $10(16,9 \%)$ & 0,295 \\
\hline Liên hệ trước với bệnh viện & $14(11,3 \%)$ & $13(20,0 \%)$ & $1(1,7 \%)$ & 0,001 \\
\hline Nhập viện trong giờ hành chính & $55(44,4 \%)$ & $38(58,8 \%)$ & $17(28,8 \%)$ & 0,001 \\
\hline Dùng hạ áp trước khi THK & $24(19,4 \%)$ & $14(21,5 \%)$ & $10(16,9 \%)$ & 0,518 \\
\hline THK tại phòng chụp & $3(2,4 \%)$ & $3(100 \%)$ & $0(0 \%)$ & - \\
\hline
\end{tabular}

Các yếu tố trên liên quan đến thời gian cửa - kim dưới 60 phút, phân tích cho thấy các yếu tố bao gồm có liên hệ trước với bệnh viện, nhập viện trong giờ hành chính có liên quan với p < 0,05.

Bảng 4. Hồi quy logistic các yếu tố liên quan đến cửa - kim

\begin{tabular}{|c|c|c|c|c|}
\hline Các biến & $\begin{array}{c}\text { Hồi quy đơn biến } \\
\text { OR (95\%CI) }\end{array}$ & $\mathbf{p}$ & $\begin{array}{l}\text { Hồi quy đa biến } \\
\text { OR }(95 \% \mathrm{CI})\end{array}$ & $\mathbf{p}$ \\
\hline Đi xe cứu thương & $0,625(0,258-1,512)$ & 0,29 & & \\
\hline Liên hệ trước với bệnh viện & $0,069(0,009-0,546)$ & 0,011 & $0,089(0,01-0,788)$ & 0,03 \\
\hline $\begin{array}{c}\text { Nhập viện trong giờ } \\
\text { hành chính }\end{array}$ & $0,288(0,136-0,608)$ & 0,001 & $0,332(0,136-0,807)$ & 0,015 \\
\hline $\begin{array}{c}\text { Khởi phát - Nhập viện } \\
\text { (OTD) }\end{array}$ & $0,997(0,990-1,003)$ & 0,33 & & \\
\hline $\begin{array}{l}\text { Nhập viện- Thăm khám } \\
\text { (DTE) }\end{array}$ & $1,092(1,041-1,146)$ & $<0,001$ & $1,077(1,021-1,137)$ & 0,007 \\
\hline NIHSS & $0,945(0,868-1,030)$ & 0,20 & $0,946(0,844-1,059)$ & 0,335 \\
\hline Dùng hạ áp trước khi THK & $0,743(0,302-1,831)$ & 0,52 & & \\
\hline THK tại phòng chụp & - & - & & \\
\hline
\end{tabular}

60 phút bao gồm: Có liên hê̂ trước với bệnh viện; Nhập viện trong giờ hành chính và Thời gian nhập viện - thăm khám ngắn.

\section{BÀN LUÂ̂N}

Tại bệnh viện Bạch Mai và Đại học Y Hà Nội, mô hình cấp cứu bệnh nhân đột quỵ nhồi máu não là tương tự nhau, phần não đã có những áp dụng của mô hình Helsinki. Các bệnh nhân khi nhập viện có các triệu chứng gợi ý đột quy não sẽ nhanh chóng được phân loại và báo động bằng biển báo cấp cứu đột quy. Bệnh nhân nhanh chóng sẽ được các bác sĩ cấp cứu đột quy. thăm khám và liên hệ với team cấp cứu đột quy. của bệnh viện. Sinh hiệu và xét nghiệm máu nhanh chóng được lấy và bệnh nhân được đưa nhanh đến phòng chụp phim sọ não. Sau khi có kết quả sơ bộ phim chụp và trao đổi giữa các bác sĩ chẩn đoán hình ảnh, cấp cứu đột quy. và thần kinh, bệnh nhân sẽ được quyết định dùng thuốc tiêu huyết khối nếu không có chống chỉ định.

Trong nghiên cứu này, đặc điểm chung ở 2 nhóm bệnh nhân có thời gian cửa - kim dưới 60 phút và $\geq 60$ phút là tương đồng nhau. Các yếu tố nguy cơ bao gồm Tăng huyết áp, Đái tháo đường, Rối loạn lipid máu, Rung nhĩ và Đột quy. não cũ̃, các yếu tố này cũng không có sự khác biệt giữa 2 nhóm.

Các nghiên cứu trên thế giới cho thây 3 bước đơn giản có thể áp dụng để làm giảm thời gian cửa - kim ở bệnh nhẩn được điều trị tiêu huyết khối bao gồm: 1) Liên hệ trước viện; 2) Đưa BN thẳng vào phòng chụp CT; 3) Tiêu huyết khối tại 
phòng chụp CT. ${ }^{9}$ Trong nghiên cứu này, có 14 bênh nhân chiếm 11,3\% được liên hệ trước với bểnh viện, nhóm này có thời gian cửa - kim ngắn hởn có ý nghĩa thống kê, trong đó 13 bệnh nhân có thời gian cửa - kim dưới 60 phút. Liên hệ trước với bệnh viện tiếp nhận có thể giúp kích hoạt sớm báo động cho nhóm đột quy, làm rút ngẳn thời gian phân loại và sắp xếp được nguồn lực (ví dụ chuẩn bị săn máy chụp phim sọ não) để cấp cứu bệnh nhân một cách nhanh chóng nhất, từ đó làm giảm được thời gian cửa - kim. Trong nghiên cứu này, có $26(21 \%)$ bệnh nhân đến viện bằng xe cấp cứu, trong số này chỉ có 6 $(4,8 \%)$ bệnh nhân có liên hệ trước với bệnh viện và nhóm đến viện bằng xe cứu thương không khác biệt so với nhóm còn lại về thời gian cửa kim, do đó nếu thiết lập được hệ thống thông tin giữa xe cấp cứu và bềnh viện tiếp nhận để liên lac khi có bệnh nhân đôt quy sẽ làm rút ngắn được thời gian đến khi điều trị. Nghiên cứu ở Bắc Ai len cho thấy đến viện bằng xe cứu thương và liên hệ trước với bệnh viện làm giảm thời gian cửa - kim.

Đặc điểm lâm sàng của các bệnh nhân lúc nhập viện, điểm NIHSS ở nhóm có thời gian cửa - kim dưới 60 phút thấp hơn nhóm $\geq 60$ phút (10 điểm so với 8 điểm), tuy nhiên sự khác biệt là không có ý nghĩa thống kê. Điều này có thể được giải thích là khi nhập viện với bệnh nhân có triệu chứng nặng hơn có thể được nhận biết sớm hơn khả năng bị đột quy. và từ đó được phân loại sớm hơn, thăm khám và can thiệp sớm hơn.

Các khoảng thời gian từ khi khởi phát triêu chứng đến khi bênh nhân được điều trị tiêu huyết khối bao gồm thời gian khởi phát - nhập viện, thời gian nhập viện - thăm khám, thời gian cửa - kim, thời gian khởi phát - điều trị ở nhóm bệnh nhân nghiên cứu lần lượt là 103 phút, 9 phút, 59 phút, 160 phút. Một nghiên cứu ở Trung Quốc năm 2015 cho thấy các khoảng thời gian này lần lượt là 110 phút, 10 phút, 116 phút và 229 phút. Có thể thấy khoảng thời gian khởi phát - nhập viện, nhập viện - thăm khám là tương tự nhau, nhưng thời gian cửa - kim kéo dài làm kéo dài thời gian từ khi bênh nhân khởi phát triêu chứng đến điều trị. Do đó, việc rút ngắn thời gian cửa - kim là cần thiết, phù hợp với tiêu chí "thời gian là não" trong cấp cứu bệnh nhân đột quy.

Thời điểm nhâp viện là môt yếu tố độc lâp liên quan đến thời gian cửa - kim dưới 60 phút. Các bệnh nhân vào viện trong giờ hành chính, được định nghĩa là $8 \mathrm{~h}$ đến $17 \mathrm{~h}$ các ngày từ thứ 2 đến thứ 6 tại bệnh viện Bạch Mai, cộng thêm sáng thứ 7 từ $8 \mathrm{~h}$ đến $12 \mathrm{~h}$ tại bệnh viện Đại học
Y Hà Nội, ngoại trừ ngày nghỉ, có thời gian cửa kim trung bình ngắn hơn các bệnh nhân vào viện ngoài giờ. Nghiên cứu ở Đan Mạch cũng cho thấy nhập viện ngoài giờ hành chính cũng làm kéo dài thời gian cửa - kim. Điêuu này có thể được giải thích là ngoài giờ hành chính chỉ có bác sĩ trực, bệnh nhân cần tham vấn ý kiến trước khi đưa ra quyết định tiêu huyết khối. Một yếu tố khác cũng ảnh hưởng là ít nhân lực làm việc hơn trong giờ trực, ở cả khoa cấp cứu và khoa chẩn đoán hình ảnh.

Rút ngắn thời gian nhập viện - thăm khám cũng là một yếu tố làm giảm được thời gian cửa kim. Trong nghiên cứu của chúng tôi, trung vị thời gian nhập viện - thăm khám là 9 phút, bệnh nhân sau khi được phân loại có thể phải chờ 1 thời gian mới được thăm khám, đặc biệt khi số lượng bệnh nhân cùng nhập viện lớn. Do đó, việc thiết lập một hệ thống báo động ngay khi nhập viện để bệnh nhân được ưu tiên thăm khám, chụp phim và can thiệp điều trị là cần thiết.

Trong các yễu tố tại bệnh viện ảnh hưởng đến thời gian cửa - kim, điêu trị tăng huyết áp là một yếu tố độc lập liên quan đến kéo dài thời gian cửa kim. Trong nghiên cứu của chúng tôi, có 24 bệnh nhân được dùng thuốc hạ áp trước khi tiêu huyết khối, tuy nhiên không có sự khác biệt giữa 2 nhóm có thời gian cửa - kim dưới 60 phút và $\geq 60$ phút, có thể do khi bênh nhân nhập viện có huyết áp cao đã được dùng thuốc hạ áp đường tĩnh mạch song song với việc được chụp phim sọ não, và sau khi có kết quả chụp phim thì tình trang huyết áp đã có đủ điều kiện để dùng thuốc tiêu huyết khối. Dùng thuốc tiểu huyết khối tại phòng chụp là một trong những biện pháp để làm giảm thời gian cửa - kim. Trong nghiên cứu của chúng tôi, có 3 bệnh nhân được dùng thuốc tiêu huyết khối tại phòng chụp $\mathrm{CT}$, cả 3 bệnh nhân này đều có thời gian cửa kim dưới 60 phút. Do hạn chế về cỡ mẫu nên chúng tôi không đánh giá sự liên quan đến thời gian cửa - kim bằng phương pháp hồi quy ở nhóm bệnh nhân này.

\section{KẾT LUÂN}

Nghiên cứu của chúng tôi mô tả môt số yếu tố liên quan đến thời gian cửa - kim ở bệnh nhân đột quy. nhồi máu não cấp được điều trị tiêu huyết khối tại 2 bệnh viện Bạch Mai và Đại học $Y$ Hà Nội có mô hình cấp cứu bệnh nhân đột quy. não tương tự nhau. Kết quả cho thấy liên hệ trước với bệnh viện, vào viện trong giờ hành chính và thời gian nhập viện - thăm khám ngắn là các yếu tố độc lập liên quan đến thời gian cửa 
- kim dưới 60 phút.

Lời cảm ơn: Chúng tôi xin chân thành cảm ơn Khoa Cấp cứu \& Hồi sức tích cực bệnh viện Đại học Y Hà Nội, Khoa Cấp cứu bệnh viện Bạch Mai.

\section{TÀI LIẸU THAM KHẢO}

1. Benjamin Emelia J, Virani Salim S, Callaway Clifton W, et al. Heart Disease and Stroke Statistics-2018 Update: A Report From the American Heart Association. Circulation. 2018;137(12):e67-e492.

2. World Health Organization. The top 10 causes of death. https://www.who.int/news-room/factsheets/detail/the-top-10-causes-of-death.

Accessed Nov 01, 2020.

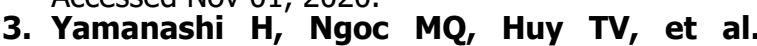
Population-Based Incidence Rates of First-Ever Stroke in Central Vietnam. PLoS One. 2016; 11(8): e0160665. Accessed 2016.

4. Micieli G, Marcheselli S, Tosi PA. Safety and efficacy of alteplase in the treatment of acute ischemic stroke. Vasc Health Risk Manag. 2009;5(1):397-409.

5. Hajjar K, Kerr DM, Lees KR. Thrombolysis for acute ischemic stroke. Journal of Vascular Surgery. 2011; 54(3):901-907.

6. Fernandes $\mathbf{D}$, Umasankar U. Improving Door to Needle time in Patients for Thrombolysis. BMJ Qual Improv Rep. 2016;5(1):u212969.w215150.

7. Man S, Xian Y, Holmes DN, et al. Association Between Thrombolytic Door-to-Needle Time and 1Year Mortality and Readmission in Patients With Acute Ischemic Stroke. JAMA. 2020;323(21):2170-2184.

8. Powers WJ, Rabinstein AA, Ackerson T, et al. 2018 Guidelines for the Early Management of Patients With Acute Ischemic Stroke: A Guideline for Healthcare Professionals From the American Heart Association/American Stroke Association. Stroke. 2018;49(3):e46-e99.

9. Meretoja A, Weir L Fau - Ugalde M, Ugalde M Fau - Yassi $\mathbf{N}$, et al. Helsinki model cut stroke thrombolysis delays to 25 minutes in Melbourne in only 4 months. (1526-632X (Electronic)).

\section{ĐÁNH GIÁ HIỄU QUẢ CỦA PHƯO'NG PHÁP GƯƠNG TRI LIỆU ĐẾN CHỨC NĂNG VÂAN ĐộNG Ở BÊNHH NHÂN LIÊTT NỬA NGƯ'ỜI DO ĐộT QUỴ NÃO TẠI BỆNH VIỆ́N Y HỌC CỔ TRUYỀN CAO BẰNG}

Vũ Thị Tâm', Nguyễn Phương Sinh ${ }^{1}$, Trịnh Minh Phong1, Dương Hồng Nhung ${ }^{2}$, Lê Thị Tuyết Chinh ${ }^{3}$

\section{TÓM TẮT}

Mục tiêu: Đánh giá hiệu quả của phương pháp gương trị liệu đến chức năng vận động ở bệnh nhân liệt nửa người do đột quỵ não. Đối tượng và phương pháp: Nghiên cứu mô tả mô tả can thiệp đối chứng trên 180 bệnh nhân bị liệt nửa người do đột quy não đã điêu trị tại bệnh viện $Y$ học cố truyền Cao Bằng thời gian từ ngày 3/7/2018 đến ngày 3/7/2020. Kết quả và kết luận: Sau 3 tháng can thiệp bằng phương pháp gương trị liệu ở nhóm can thiệp có $94,44 \%$ ngồi vững (trước điều trị 73,33\%). Có $64,44 \%$ bệnh nhân tự đi lại được (trước tập là $32,22 \%$ ). Mức độ vận động bàn tay liệt gia tăng sau thời gian điêu trị 3 tháng ở cả hai nhóm, kết quả ơ nhóm can thiệp cải thiện rõ rệt hơn so với nhóm chứng với mức đô vân đồng tốt và khá đến 75,56\% (nhóm chứng chiếm $52,22 \%$ ). Mức độ khéo léo bàn tay liêt gia tăng sau thời gian điều trị 3 tháng, với mức độ khéo léo 4,5,6 là mức độ khéo léo nhất chiếm $56,66 \%$ (trước điều trị 2,22\%).

\footnotetext{
${ }^{1}$ Trường đại học Y Dược Thái Nguyên ²Bệnh viện Trung Ương Thái Nguyên ${ }^{3}$ Bệnh viện Y học cổ truyền Cao Bằng Chịu trách nhiệm chính: Vũ Thị Tâm Email: bstamphcn@gmail.com Ngày nhận bài: 22.10.2020 Ngày phản biện khoa học: 25.11.2020 Ngày duyệt bài: 7.12.2020
}

Tư khóa: Đột quỵ não, phục hồi chức năng, vật lý trị liệu, nhồi máu não, vận động trị liệu, gương trị liệu.

\section{SUMMARY}

THE EFFECTIVENESS OF COMBINATION OF MIRROR THERAPY IN REHABILITATION FOR MOTOR FUNCTION IN PATIENTS WITH HEMIPARESIS DUE TO STROKE IN CAO BANG HOSPITAL OF TRADITIONAL MEDICINE

Objective: To assess the effectiveness of combination of mirror therapy in rehabilitation for moto function in patients with hemiparesis due to stroke. Subjects and methods: intervention study controlled trial with 180 patients, who were hemiparesis due to stroke, are treated in Cao Bang hospital of traditional medicine in the period from July, $3^{\text {rd }} 2018$ to July, $3^{\text {rd }} 2020$. Results and conclusions: After 3 months of program, within intervention proup, $94,44 \%$ patients had good sitting ability (the firgure before intervention is $73,33 \%$ ), and $64,44 \%$ patients are able to walk by themselves (the firgure before intervention is $32,22 \%$ ). The hand moto function increased in both intervention and control group; however, the result of intervention group was more effective than of control group in terms of excellent and good moto function, at 75,56\% compared with $52,22 \%$. Level of hand dexterity in paralyzed hand increased after 3 months of program, with level 4,5,6 being the most skillful level, accounting for $56.66 \%$ (before intervention 2.22\%). 